However, a careful history revealed that mild symptoms of endocrine dyscrasia oxisted before the development of a fullblown hypopituitarism. Menarche at 15 was followed by sporadic bleedings of varying duration (from a few hours to 14 days), always with scanty flow. Frequent spells of depresion were explained by the family physician as a " minor defect self-correctable by marrage." Marriage at 22 somewhat regularized sligomenorrhoeic menses. Married life, however, was unsatisfactory. She experionced no orgasms and coitus was regarded only as a necessity for reproduction. After marriage, the "moody" spells became more frequent and alternated with mild euphoria.

After prolonged therapy with chorionic gonadotropins the patient achieved pregaancy in the sixth year of marriage. The uneventful pregnancy ended by low-forceps telivery. However, a mild haemorrhage followed the manual removal of the retained placenta. A complete absence of milk prohibited breast-feeding.

Menses never returned after birth of the shild. The spells of deep depressions with periodic psychomotor outbursts required institutionalization. Several courses of insulin ind electric shock therapy over a five-year period did not alter the course of the disease. Eventually the endocrinological work-up stablished the true picture of the metabolic lerangement.

Physical examination revealed a short and sbese female with peri-orbital oedema, scanty pubic and axillary hair, B.P. 90/60, pulse 58, slow tendon reflexes, and no -litoral and vaginal reflexes.

Laboratory studies: urinalysis normal ; complete blood count showed mild hypochromic anaemia; syphilis serology negative ; blood creatinine $0.6 \mathrm{mg} . / 100 \mathrm{ml}$; 便 acid $6.8 \mathrm{mg}$./ $100 \mathrm{ml}$.; insulin tolerance test ended in an acute hypoglycaemic reaction with 20 mg./100 ml. glycaemia. Glucose tolerance test also ended in hypoglycaemic reaction at $35 \mathrm{mg} .100 \mathrm{ml}$. glycaemia. P.B.I. $1.8 \mu \mathrm{g} /$ $100 \mathrm{ml}$. rose to $6.8 \mu \mathrm{g}$. $/ 100 \mathrm{ml}$. after stimulation with 10 units T.S.H.; radioactive $I^{131}$ uptake was $7 \%$ with the conversion ratio $5 \%$; sedated basal metabolic rate minus $46 \%$ and minus $48 \%$; urinary gonadotropins reduced; 17-ketosteroids in 24 hour urine $=3.7 \mathrm{mg}$.; 17 hydroxysteroids $=$ $0.1 \mathrm{mg}$.; pregnanediol and pregnanetriol were absent; E.C.G. showed low voltage in ill leads, otherwise normal; $x$-ray of the ikeleton unremarkable; vaginal epithelium showed poor cornification.

The diagnosis was established as panbypopituitarism with accompanying syndromes of hypothyroidism, hypocorticism, and hypo-ovarism.

Replacement therapy consisted of triiodothyronine with tetra-iodothyronine prednisolone, and oestrogens supplemented with thyroid, adrenal, and ovarian tropic tormones (T.S.H., A.C.T.H., F.S.H.). A somplete remission with an establishment of a regular menstrual cycle occurred within six months.

In the other two patients with Sheehan's syndrome several spontaneous abortions preceded the critical pregnancy, which was followed by the development of acute pan-hypopituitarism.

In appraising these three patients it is important to note that all possessed a mild hypothalamic inadequacy with poor contractility of uterine muscle leading to the delayed expulsion of the foetus and/or detachment of the placenta, and atonic haemorrhage. In other words, the dramatic events of the delivery in the form of haemorrhage are the result of a hormonal insufficiency brought about by pre-existing disease in the hypothalamus and/or hypophysis. The symptoms then became more pronounced after the post-partum haemorrhage and so have led to an erroneous interpretation of the exact nature of the disease. -I am, etc.

$$
\begin{aligned}
& \text { Chicago 2, } \\
& \text { Illinois, U.S.A. }
\end{aligned}
$$

\section{Z. Z. GoDLowsKI.}

\section{$X_{\text {Penicillin in Milk }}$}

SIR,-Two years ago I reported the case of a woman who developed dermatitis which proved to be a hypersensitivity reaction to the minute amounts of penicillin in normal bulked milk supplies. ${ }^{1}$ Two attempts at desensitization had failed. Subsequently she was treated by adding penicillinase to her milk. When she had remained free of her eruption for 14 months a further attempt was made to desensitize her, which was entirely successful. Soluble penicillin G was given by mouth, beginning with 0.1 unit daily and increasing over a period of five months to 15,000 units a day. Over the final two months the addition of penicillinase to her milk was gradually discontinued. She has now remained completely well for a year on a full normal diet.-I am, etc.,

London W.1.

\section{P. BORRIB.}

\section{ReferenCB}

: Borric, P., and Barrett, J., Brit. med. J., 1961.

\section{Ingrowing Toenails}

SIR,-Mr. A. W. Fowler in his letter (November 2, p. 1131) has, I am sure, explained why toenail surgery remains in the doldrums. I am less certain that he has suggested the correct cure. Our thesis ${ }^{1}$ is that the conservative management of ingrowing toenails can be carried out by the patients themselves, under the supervision of their own general practitioner, the casualty department of any hospital, or under the care of a chiropodist.

It cannot be denied that very variable results have been obtained with all methods of nail-bed ablation, including the method described originally by Quenu, ${ }^{2}$ in which the germinal matrix alone is excised. I would agree with $\mathrm{Mr}$. Fowler that this operation can give excellent results, but it requires interest, a meticulous technique, and experience. If, therefore. toenail surgery is to be lifted from the doldrums, I am convinced that this can only be achieved by supervision and teaching of those who carry out any form of operation on the nail bed.

Until nail-bed ablation becomes a more universally satisfactory technique I am convinced that the ingrowing toenail should be treated energetically by conservative means, and any patient requiring nail-bed ablation, for which there are undoubted specific indications, should have a carefully planned and carried out operation, and hence a good end-result I am, etc.,

R. W. LLOYd-DAviz8.

Kent and Canterbury Hospital

Canterbury, Kent.

\section{REFERENCES}

1 Lloyd-Davies, R. W., and Brill, G. C., Brt. Surg., 1963, 50, 592.

Fowler, A. W., ibid., 1958, 45, 382.

\section{Training for General Practice}

SIR,-In a recent monograph entitled Doctor and Patient. Ethics, Morale. Government ${ }^{1}$ and given prominent publicity in The Times, Sir Robert Platt has drawn attention to the necessary postgraduate training prior to entry into general practice. He suggests a period of three, and preferably five, years' postgraduate training, whereby " the whole status of general practice would improve and the public have direct access to a higher quality of medical care."

There must be many of us who agree with Sir Robert Platt, but has adequate consideration or encouragement really been given to those who would wish to embark upon such a course? Granted the fact that the first year's pre-registration post should be treated very much as a provisional period, what of the following years ? A midwifery appointment is essential; a casualty, paediatric, and further medical appointments are certainly desirable, to say nothing of psychiatry and the "minor specialties," all important in general practice.

One has therefore to exist on, at the most, f1,200 per annum (senior house officer grade), or if the job is particularly good and therefore receives many applications, £980 (house officer grade). If one is married, a separate home for wife and perhaps family has to be provided out of this income. Added to that, one is often doing work or taking decisions that one feels general practitioners would have taken had they been similarly trained.

Why, therefore, penalize so heavily those who wish to provide in the future what is at present described as " the best form of general practice"? Can cne wonder that one's contemporaries seek the relative security of general practice at the earliest possible opportunity ? -1 am, etc.,

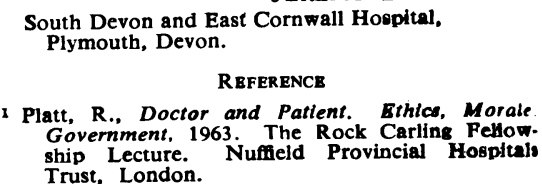

\section{Mental Retardation}

SIR,- - The correspondence about appro priate terms to describe individuals with intelligence less than "normal" implies that there is agreement in the United States about the use of the term " mental retardation." This is not reflected by the 
literature. The American Journal of Mental Deficiency of May, 1958, contains two major review articles: one uses mental retardation to describe the whole field of mental deficiency, ${ }^{1}$ while the other restricts the term to cases in which "no pathology is ... detectable and environmental deficits provide the causal explanations."”

We would make a plea that the term "mental retardation" be reserved for this non-organic category of patients, although with some further qualifications. Mental deficiency (or mental subnormality) has many causes. Only some of these fit the concept of a permanent intellectual deficit usually present at birth and persisting through growth and development to maturity. We believe, with others, that some causes can retard the development of minds normal at the outset ${ }^{3}$ : we have recently presented evidence which may help to define some of the characteristics of one such form of retardation." This retardation, which thus becomes apparent during development, is to some extent recoverable.

The syndrome of mental retardation would include most of those cases of mental subnormality designated by Lewis as "subcultural," by Doll as "pseudodefective," and by Penrose as "residual," as well as some of those designated by Tredgold as "primary amentia." and by others as "garden variety." -We are, etc.,

\section{ZeNa Stein.}

MERVYN SUSSER.

\section{Department of Social and Preventive}

Medicine,
University of Manchester.

\section{REFERENCES}

' Masland, R. L., Amer. J. ment. Defic., 1958, 62, 991.

Sarason, S. B., and Gladwin, T., ibid., 1958, 62, 1115.

Clarke, A. D. B., Clarke, A. M., and Reiman, S., Brit. J. Psychol., 1958, 49, 144.

W. Amer. J. ment. Defic.. 1963, 67, 811 .

- Lewis, E. O., J. ment. Sci., 1933, $79,298$.

- Doll, E. A., Amer. J. ment. Defic. 1947, 51, 420 1954, L. S. The Biology of Mental Defect, Tredgold, A. F. A A Textbook of Menial Deficiency, 1907. Baillière, Tindall and Cox London.

- Sarason, S. B., Psychological Problems in Mental Deficiency, 2nd ed., 1953. Harper, New York.

\section{Handicapped Children}

SiR,-We read with interest your leading article on "Children at Risk of Handicap" (July 27, p. 193) and the comments of your correspondents (August 17, p. 443, and September 14, p. 685) on this subject.

In our opinion the value of knowing that the child is " at risk" is in alerting medical and public health personnel, so that the early diagnosis of the suspected physical or mental deficit allows for adequate medical, educational, and rehabilitative procedures to be instituted.

A Registry for Handicapped Children has been in operation in the Province of British Columbia for eleven years. Its chief function has been to ensure that the handicapped children of the Province do have full opportunity for proper medical, educational, and rehabilitative care. It has also resulted in the accumulation of valuable incidence and prevalence statistics. In the light of your article, we have given some thought to how a "risk register " may supplement the Registry for the Handicapped now in existence and have the following points to make.

First, it is apparent in retrospect that a large number of the children now on the British Columbia Registry would have been on a "risk register" if one had been in existence. Second, a "risk register" or listing does seem worth while on a local health unit level by making the health officer and staff aware of those children or families (in the case of recurrent problems) which might merit special attention and to ensure promp registration in the Registry for the Handicapped if the potential disability becomes manifest.

In our opinion it is most important that a register for the handicapped is based on a large population in order to provide a central reporting area which allows for the collection and compilation of accurate statistics on all handicapping or potentially handicapping conditions.-We are, etc.,

Donald Paterson.

JAMES R. MilleR.

ANNIE E. Scott.

Registry for Handicanped Children.

Health Services and

Hospital Insurance,

Vancouver 9. B.C., Canada.

\section{Central Sterilization}

SIR,-Reading the description of the "Edinburgh Pre-set Tray System" (November 23, p. 1322), I was interested to compare this experiment with that carried out at this hospital at High Wycombe over the last three years. Here we have used packs in theatre supplied by the C.S.S.D. No sterilization of any sort is done in the theatre suite. Details of the system may be found in The Hospital $^{1}$ and the Lancet."

Briefly all packs for theatre are packed in the C.S.S.D., which also serves the rest of the hospital. Before each list the packs are delivered to theatre, where they are stored in what used to be the sterilizing room. As at Edinburgh only when the patient is on the table are the packs opened.

While the Edinburgh system has the decided advantage that there is no laying up to be done in theatre there are several other points which we at High Wycombe would not feel altogether happy about:

1. The use of only three sizes of tray must result in considerable bulk. We use a system of a few comprehensive packs together with supplementaries, so that even though there are about 100 packs many of them are very small. With this system we feel that we have gained the advantage of standardization but without the disadvantage of forcing inflexible practice. We have also found that it is useful to be able to pack some items in transparent nylon film in order that size mav be checked before opening.
2. At Edinburgh considerable ingenuity has been used to overcome drying difficulties occasioned by the use of trays. We have found that by using paper wrappers and purpose-designed cardboard boxes this difficulty does not arise.

3. We have also noticed an increased demand for the autoclave, but only to the extent that it is now used more consistently throughout the day.

4. The increase in instruments quoted by Edinburgh seems phenomenal. At High Wycombe we examined every procedure and as a result have been able to make savings in the number of instruments laid up. We found that in some cases custom, not practice. had stipulated the numbers of instruments laid up. For instance, we were able to cut down the number of Spencer Wells. as we are now using more diathermy. The result of this review was that very few extra instruments have had to be provided because of the new system.

5. In the new High Wycombe hospital the C.S.S.D. will operate two work streams, the inner one for the theatres sited above it and connected by "clean" and "dirty" hoists. and the outer one for the rest of the hospital. It is not contemplated that there will be any difficulty in adapting the present system, which only serves 150 beds, one theatre. and very busy accident and out-patien departments, to deal with three theatres and up to 1,000 beds.

Finally, it is encouraging to know that not everyone is being deterred by the often repeated cry that central sterilizing of theatre instruments will not work both Edinburgh and High Wycombe have shown that it can work most successfully. -I am, etc.

N. F. Sparrow.

\section{War Memorial Hospital \\ High Wycombe, Bucks. \\ REFERENCES \\ Sparrow, N. F., and Wall, A., Hospital, 1963. 59, 397. H. Taylor, K.}

\section{Chronic Pneumonitis and Asbestosis}

SIR,-In your issue of November 2. p. 1130. Dr. Paul Gross refers to a letter of mine of January 12, 1963, on exposure to asbestos dust and diffuse pleural mesotheliomas. He states that $\mathrm{my}$ diagnosis of basal asbestosis seems to depend upon the recognition of a limited slight chronic interstitial pneumonitis in conjunction with the finding of one or several isolated asbestos bodies in lung juice. He further credits me with the assumption that the very small amount of asbestos dust which may be found in urban air is sufficient to produce basal asbestosis. The bulk of his letter is a reasoned and reasonable evaluation of these two opinions, and his conclusion is that one should be cautious in accepting them.

These opinions, however. are not my opinions. In the paper referred to by $\mathrm{Dr}$ Gross we clearly stated that it was only in those cases with abundant asbestos bodies in smears from the lung bases that 